\title{
Cancer Is the Innate Immunity Fault
}

\author{
Vladimir N Pak* \\ Freelance researcher, Toronto, Canada
}

Submission: July 30, 2017; Published: August 01, 2017

*Correspondence Address: Vladimir N Pak, Freelance researcher, Toronto, Canada, Email: oncoshut@gmail.com

Abstract

While a large portion of cancer immunotherapy's focus on targeting T cells, there has been a surge of interest in harnessing the relatively underexplored NK system for therapeutic intervention. Unlike adaptive immunity innate one starts working immediately with low number of cells and can become the new generation of cancer prophylactic and ordinary immunotherapy. Innate immunity is locally blocked in the cases of embryo cells and cancer stem cells or metastases due to mechanisms that are triggered in the immune system by these types of cells.

If you can look into the seeds of time, And say which grain will grow and which will not, Than speak to me.

W. Shakespeare

One of the triggers is AFPR that is expressed by embryo cells and re-expressed by the majority of cancer cells. AFPR binds its ligand-AFP loaded with the nutrients. AFP shuttles nutrients from microenvironment to AFPR-positive cells. In addition to embryo and cancer cells the host immune system MDSC are also AFPR-positive. As the top cells in immune hierarchy MDSC are able to suppress both innate and adaptive immunity. Local accumulation of MDSC and AFP provides indulgence to cancer cells. MDSC depletion can awake innate immunity NK and adaptive immunity T-cells to destroy cancer cells. One of the ways to deplete MDSC is AFP-toxin drug. Combined action of innate and adaptive immunity plus targeted chemotherapy all provided by AFP-toxin drug is beneficial for cancer patients.

Keywords: Cancer; Alpha-Fetoprotein Receptor; Myeloid-Derived Suppressor Cells; MDSC-Targeted Immunotherapy; Major Histocompatibility Complex Class I

Abbreviations: AFP: Alpha-Fetoprotein; AFPR: Alpha-Fetoprotein Receptor; MDSC: Myeloid-Derived Suppressor Cells; NK: Natural Killer Cells; MHC class I: Major Histocompatibility Complex Class I; 5FU: 5-Fluorouracil

\section{Introduction}

Dr. Coley boosted the immune system to attack cancer cells by bacteria toxins and some patients with certain types of cancer had shrinkage of the cancer or lived longer than expected [1]. The stimulated human immune system is a whirling tempest of different physiological and biochemical responses. One theory stresses the importance of the fluid-induced fever (innate immunity response) in destroy the cancer cells; another considers the debris-engulfing macrophages (innate immunity cells) to be the main players, while others consider various different cytokines to be important. In any case innate immunity is involved in the anti-cancer reaction induced by Dr. Coley's toxin. Both innate and adaptive immune cells actively prevent neoplastic development in a process called "cancer immunosurveillance".

Innate immune cells, including monocytes, macrophages, dendritic cells and NK, mediate immediate, short-lived responses by releasing cytokines that directly lyse tumour cells or capture debris from dead tumour cells. Adaptive immune cells, including
$\mathrm{T}$ and $\mathrm{B}$ cells, mediate long-lived, antigen-specific responses and effective memory. The understanding of how the immune system works has developed a lot since Dr. Coley's time [2], so current immunotherapy treatments works much better. Today the purified molecules and drugs are used to target definite immune cells to stimulate or de-block the immune system to destroy cancer cells. Modern checkpoint inhibitors or CAR-T cell immunotherapy's relay on adaptive immunity T-cells [3] while other powerful arm of immune system - innate immunity with its macrophages and NK - is not yet fully utilized in cancer treatments. It could be beneficial for the cancer patients to have immunotherapies that combine both adaptive and innate immunity.

Embryo, cancer, cancer stem cells or metastases all start from the single cell. At the early steps of their proliferation it is innate immunity that can recognize and eliminate them while adaptive immunity needs bigger cells numbers and time to generate specific response. To be effective T-cells immunotherapy needs 
cancer specific and MHC class I antigens while cancer cells can get rid of them [4,5]. On the other hand, innate immunity NK does not need neither specific antigens no MHC class I antigens to destroy the cell [6]. Due to cancer cells intervention at high immune regulatory level both innate and adaptive immunity does not work in metastases. One of the immune modulation tools is AFPR that is expressed by embryo cells and re-expressed by majority of cancer cells $[7,8]$. AFPR is much more universal tumor marker than its ligand - AFP [9] that is why we can assume that AFPR-positive cancer cells that do not produce AFP themselves have to utilize the host one generated during regeneration and hematopoiesis.

AFP naturally loaded with essential nutrient polyunsaturated fatty acids stimulates embryo cells proliferation and simultaneously prevents the rejection of an embryo by the maternal immune system by MDSC activation [10,11]. AFPR specifically absorbs AFP loaded with nutrients and AFPAFPR shuttle delivery system helps cancer cells and MDSC to proliferate. AFPR-positive MDSC is one of the minor immune cells subpopulation [12-14]. Being fed with AFP-nutrient complexes MDSC enhances its suppressive activity. As the hierarchy top immune cells MDSC suppresses both innate and adaptive immunity [15-17]. MDSC activity or damage has a huge effect on subordinate regulatory immune cells and directly on NK and T-cells. MDSC migrate from the bone marrow to problem places (injury, inflammation, regeneration, cancer, etc.) and suppress immune system in a complex way, including innate immunity NK in particular $[6,18]$. Accumulation of MDSC and AFP (native or cancer cells-origin) in cancer cells microenvironment makes immune system tolerable to cancer. That is why MDSC is a perfect target for immunotherapy $[19,20]$ and AFP-AFPR delivery system utilization by cancer cells is its "Achilles heel" [21]. MDSC depletion breaks immune tolerance to cancer and became a new generation of immunotherapy that unleashes combined T-cells and NK attack to cancer cells.

Unlike chemotherapy MDSC-immunotherapy does not need high toxin doses to reach $100 \%$ cells to be destroyed thus avoiding chemotherapy bystander toxicity. For example, $5 \mathrm{FU}$ was shown to deplete MDSC in lower doses than it was used as chemotherapy [22]. Another example: the antitumor effects of paclitaxel are generally attributed to the suppression of microtubule dynamics resulting in defects in cell division. Resent data demonstrated that in ultralow non-cytotoxic concentrations, paclitaxel significantly decreased accumulation and immunosuppressive activities of tumor-infiltrating MDSC without alterations of the bone marrow hematopoiesis. The production of mediators of chronic inflammation in the tumor milieu also was diminished.

The ability of paclitaxel in a non-cytotoxic dose to block the immunosuppressive potential of MDSC in vivo represents a new therapeutic strategy to down regulate immunosuppressant and chronic inflammation in the tumor microenvironment for enhancing the efficacy of concomitant anticancer therapies [23]. Moreover, paclitaxel targeted delivery to MDSC can be provided by AFP, and AFP-paclitaxel complex significantly reduced tumor growth and improved mice survival rates [24]. Even a fraction of inactivated MDSC unleashes NK and T-cells that are capable to destroy $100 \%$ of cancer cells. MDSC-targeted immunotherapy needs lower drug doses compared to T-cells immunotherapy because T-cells are only one arm of many MDSC subordinates. Several agents were already used to specifically deplete MDSC [25-28]. These agents are in need as they can overcome in efficacy other anti-cancer immunotherapies or can be combined with them [29-31]. Vaccination with AFP, AFPR and their complexes can rise immune response to AFPR-positive MDSC and consequently to cancer cells [32].

We have demonstrated that MDSC has AFPR and can be depleted by AFP-toxin drug [33]. The discovery represents a breakthrough in the ability to understand the immune system and to use it in the fight against cancer and gives a new tool to increase immune response against cancer. It also retrospectively explains our previous results in metastases treatments with AFP-toxin drugs [34, 35]. These good results assumed to be due to a summary action of the targeted chemotherapy and MDSCimmunotherapy [36].

\section{Conclusion}

Innate immunity play critical role in the early recognition and elimination of invaders and it can be utilized for cancer cells destroy. Cancer is not eliminated at cancer stem cells and metastases stage due to the innate immunity fault. Unlike adaptive immunity T-cells innate immunity NK are able to solve nowadays-main oncology problem - destroy cancer stem cells and metastases $[37,38]$. Unfortunately, NK stay in a "split anergy" state [39] due to MDSC activity. MDSC depletion can reverse immune tolerance to cancer. Manipulation of MDSC pathway represents a new targeting strategy to promote immune-cell rejection of cancer. MDSC-targeted immunotherapy alters the overall immune responseand has advantage over checkpoint inhibitors as it activates not only adaptive immunity T-cells but innate immunity NK too. Combined T-cells and NK immunotherapy is more powerful than T-cells immunotherapy alone. MDSC-targeted immunotherapy can be done with different agents. In our research we have used AFP-toxin noncovalent complexes that luckily combines cancer cells-targeted chemotherapy with MDSC-targeted immunotherapy and have shown good results in patients with metastases.

\section{References}

1. Coley WB (1926) The Cancer Symposium at Lake Mohonk. American Journal of Surgery 1(4): 222-225

2. Medzhitov R (2007) Recognition of microorganisms and activation of the immune response. Nature 449(7164): 819-826.

3. Tumeh PC, Harview CL, Yearley JH, Shintaku IP, Taylor EJ, et al. (2014) PD-1 blockade induces responses by inhibiting adaptive immune resistance. Nature 515(7528): 568-571. 


\section{Cancer Therapy \& Oncology International Journal}

4. Aptsiauri N, Garcia-Lora AM, Garrido F (2014) 'Hard' and 'soft' loss of MHC class I expression in cancer cells. In: Tumor immunology and immunotherapy. Ed Robert C Rees Oxford University Press, England, UK, p. 63.

5. Fruci D, Benevolo M, Cifaldi L, Lorenzi S, Monaco EL, et al. (2012) Major histocompatibility complex class i and tumour immuno-evasion: how to fool $\mathrm{T}$ cells and natural killer cells at one time. Current Oncology 19(1): 39-41.

6. Cheng M, Chen Y, Xiao W, Sun R, Tian Z (2013) NK cell-based immunotherapy for malignant diseases. Cell Mol Immunol 10(3): 230252

7. Mizejewski GJ (2014) The adenocarcinoma cell surface mucin receptor for alpha-fetoprotein: is the same receptor present on circulating monocytes and macrophages? A commentary. Tumor Biol 35(8): 7397-7402.

8. Mizejewski GJ (2013) Review of the adenocarcinoma cell surface receptor for human alpha-fetoprotein; proposed identification of a widespread mucin as the tumor cell receptor. Tumor Biol 34(3): 13171336.

9. Sell S (2016) Alpha-fetoprotein in development, after liver injury, during chemical hepatocarcinogenesis and in liver cancer: how the study of alpha-fetoprotein led to the concept of cancer stem cell. Nova Science Publishes, New York, USA, p. 21-38.

10. Svensson-Arvelund J, Mehta RB, Lindau R, Mirrasekhian E, RodriguezMartinez H, et al. (2015) The human fetal placenta promotes tolerance against the semiallogeneic fetus by inducing regulatory $\mathrm{T}$ cells and homeostatic M2 macrophages. J Immunol 194(4): 1534-1544.

11. Ostrand-Rosenberg S, Sinha P, Figley C, Long R, Park D, et al. (2017) Frontline Science: Myeloid-derived suppressor cells (MDSCs) facilitate maternal-fetal tolerance in mice. J Leukoc Biol 101(5): 1091-1101.

12. Dai J, Gazzar ME, Li GY, Moorman JP, Yao ZQ (2015) MDSCs in infection and immunity. J Innate Immun 7(2): 116-126.

13. Musolino C, Allegra A, Pioggia G, Gangemi S (2017) Immature myeloidderived suppressor cells: A bridge between inflammation and cancer. Oncol Rep 37(2): 671-683.

14. Gabrilovich DI (2017) Myeloid-derived suppressor cells. Cancer Immunol Res 5(1): 3-8.

15. Gabrilovich DI, Nagaraj S (2009) Myeloid-derived suppressor cells as regulators of the immune system. Nat Rev Immunol. 9(3): 162-174.

16. Gabrilovich DI, Ostrand-Rosenberg S, Bronte V (2012) Coordinated regulation of myeloid cells by tumours. Nat Rev Immunol 12: 253-268.

17. Condamine T, Ramachandran I, Youn JI, Gabrilovich DI (2015) Regulation of tumor metastasis by myeloid-derived suppressor cells. Annu Rev Med 66: 97-110.

18. Cho D, Kim S, Caron III WE (2011) NK cell-based immunotherapy for treating cancer: will it be promising? Korean J Haematol 46(1): 3-5.

19. Wesolowski R, Markowitz J, Carson W (2013) Myeloid derived suppressor cells - a new therapeutic target in the treatment of cancer. J Immunother Cancer 1(1): 10.

20. Belyaev NN (2014) Myeloid-derived suppressor cells (MDSC) as a main tumor induced negative regulators of cancer immunity and possible ways for their elimination. KazNU Bulletin Biology series 1(60): 79-83.

21. Pak V (2017) Achilles heel of cancer. Canc Therapy \& Oncol Int J 3(5): 555625.

22. Vincent J, Mignot G, Chalmin F, Ladoire S, Bruchard M, et al. (2010) 5-Fluorouracil selectively kills tumor-associated myeloid-derived suppressor cells resulting in enhanced T cell-dependent antitumor immunity. Cancer Res 70(8): 3052-3061.
23. Sevko A, Michels T, Vrohlings M, Umansky L, Beckhove P, et al. (2013) Antitumor effect of paclitaxel is mediated by inhibition of myeloidderived suppressor cells and chronic inflammation in the spontaneous melanoma model. J Immunol 190(5): 2464-2471.

24. Alpha-cancer technologies(2017) Immunotherapy Platform, Toronto, Ontario, Canada.

25. Gujar SA, Clements D, Dielschneider R, Helson E, Marcato P, et al. (2014) Gemcitabine enhances the efficacy of reovirus-based oncotherapy through anti-tumour immunological mechanisms. Br J Cancer 110(1): 83-93.

26. Qin H, Lerman B, Sakamaki I, Wei G, Soungchul C, et al. (2014) Generation of a new therapeutic peptide that depletes myeloid-derived suppressor cells in tumor-bearing mice. Nat Med 20(6): 676-681.

27. Wilkerson A, Kim J, Huang AY, Zhang M (2017) Nanoparticle systems modulating myeloid-derived suppressor cells for cancer immunotherapy. Curr Top Med Chem 17(16): 1843-1857.

28. Wang HF, Ning F, Liu ZC, Wu L, Li Z-Q, et al. (2017) Histone deacetylase inhibitors deplete myeloid-derived suppressor cells induced by $4 \mathrm{~T} 1$ mammary tumors in vivo and in vitro. Cancer Immunol Immunother 66(3): 355-366

29. Wang Z, Liu Y, Zhang Y, Shang Y, Gao Q (2016) MDSC-decreasing chemotherapy increases the efficacy of cytokine-induced killer cell immunotherapy in metastatic renal cell carcinoma and pancreatic cancer. Oncotarget 7: 4760-4769.

30. Draghiciu O, Lubbers J, Nijman HW, Daemen T (2015) Myeloid derived suppressor cells - an overview of combat strategies to increase immunotherapy efficacy. Oncoimmunology 4(1): e954829.

31. Iclozan C, Antonia S, Chiappori A, Chen DT, Gabrilovich D (2013) Therapeutic regulation of myeloid-derived suppressor cells and immune response to cancer vaccine in patients with extensive stage small cell lung cancer. Cancer Immunol Immunother 62(5): 909-918.

32. Govallo VI (1993) The immunology of pregnancy and cancer. Nova Science Publishers Inc, Commack, New York, USA.

33. Pak VN, Belyaev NN (2016) Alpha-fetoprotein-mediated immune tolerance and its reversal. In: Alpha-fetoprotein: Functions and Clinical Applications. Nova Science Publishes, New York, USA, pp. 353-374.

34. Pak V, Molchanov O, Vincent M (2007) Treatment of metastatic colorectal cancer with aimpila, a glycoside/alpha-fetoprotein complex. J of ClinOncol 25: 160

35. Pak V (2014) The use of alpha-fetoprotein for the delivery of cytotoxic payloads to cancer cells. Ther Deliv 5(8): 885-892.

36. Pak V (2016) Magic bullet and immunotherapy against metastasis. J Cancer Prev Curr Res 6(3): 00206.

37. Jewett A, Tseng HC, Arasteh A, Saadat S, Christensen RE, et al. (2012) Natural killer cells preferentially target cancer stem cells; role of monocytes in protection against NK cell mediated lysis of cancer stem cells. Curr Drug Deliv 9(1): 5-16.

38. Tallerico R, Garofalo C, Carbone E (2016) A New Biological Feature of Natural Killer Cells: The Recognition of Solid Tumor-Derived Cancer Stem Cells. Front Immunol 7: 179.

39. Belyaev NN, Abramova VA (2014) Transmission of "split anergy" from tumor infiltrating to peripheral NK cells in a manner similar to “infectious tolerance". Medical Hypothesis 82(2): 129-133. 
This work is licensed under Creative Commons Attribution 4.0 License

DOI: $10.19080 /$ CTOIJ.2017.06.555687

\section{Your next submission with Juniper Publishers} will reach you the below assets

- Quality Editorial service

- Swift Peer Review

- Reprints availability

- E-prints Service

- Manuscript Podcast for convenient understanding

- Global attainment for your research

- Manuscript accessibility in different formats ( Pdf, E-pub, Full Text, Audio)

- Unceasing customer service

Track the below URL for one-step submission https://juniperpublishers.com/online-submission.php 